\title{
Labour market performance of young migrant workers with heterogeneous educational trajectories in China
}

\author{
Nan Xiang ${ }^{1}$ (D) Yuxi Zhang ${ }^{2}$ (D)
}

Received: 13 October 2020 / Accepted: 11 December 2020 / Published online: 22 January 2021

(c) The Author(s) 2021

\begin{abstract}
Successful global cities present a spectrum of development strategies but share the benefit of the reciprocal dynamics between tailored education systems and matching labour markets. This paper examines burgeoning cities in China and investigates the effects of the heterogeneous educational trajectories of young migrant workers in urban China on their labour market performance. Drawing on the National Migrant Dynamics Monitoring Survey, this paper finds striking wage variations among the young migrant population. Migrant workers who attended high schools in current receiving cities earned less than their counterparts who received senior-secondary education elsewhere. Students following the academic track were better off than students following the vocational track. To further explore what has prevented the urban labour market from rewarding migrants who studied in a receiving city, where the education system is expected to better cater to the city's specific industrial needs, we tested and found evidence of the mediating effects of job industry and occupation. In addition to engaging with empirical debates in the field, this paper develops a theoretical framework to model how the qualitative attributes of an education system affect wage variations among migrant workers.
\end{abstract}

Keywords Urbanisation · New-generation migrant workers · Education · Labour market returns

Yuxi Zhang

yuxi.zhang@spi.ox.ac.uk

Nan Xiang

nan.xiang@link.cuhk.edu.hk

1 Department of Sociology, The Chinese University of Hong Kong, Shatin, Hong Kong

2 Department of Social Policy and Intervention, University of Oxford, Barnett House, 32

Wellington Square, Oxford OX1 2ER, UK 


\section{Introduction}

China has enjoyed economic growth at a steady rate for four decades, powered by the large-scale domestic migration of workers who have pumped low-cost labour resources into urban manufacturing hubs (Fan 2008; Knight et al. 2011). However, China has gradually been losing its demographic dividend, and the workforce has started to shrink (Cai and Du 2011). Therefore, the labour market participation of the younger generation of migrant workers is the foundation for the future development of cities (Wang and Mason 2007). In the industry-upgrading transition, whether young migrants are able to convert investment in education to commensurate wages forecasts their likelihood of escaping from a middle-income trap that is looming in many metropolitan areas in the Global South (Khor et al. 2016).

The cross-border immigration literature has found that the 'penalty of education' phenomenon affects the wages of immigrant workers. First-generation immigrants often have to undertake low-pay jobs requiring skills lower than what they possess. The difficulty for an immigrant to earn a wage equal to that of an indigenous worker at the same education level, in effect, punishes immigrants in terms of their investment in education (Chevalier 2003; Wen and Maani 2017). Domestic migrants in China bear a similar penalty when compared with locals with a similar level of education. To account for the reasons behind this discrepancy, many scholars have identified the institutional barriers of household registration (the hukou system), industrial segregation and employment discrimination (Liu et al. 2017; Wang et al. 2015, 2019; Xiao and Bian 2018).

Recently, researchers have begun to pay attention to the intragroup heterogeneity of migrant workers, particularly the 'new-generation migrant workers' born during or after the 1980s. Lyu and Chen (2019) explore the wage differences among migrants born after the 1980s. However, they mainly investigate the correlation between the parent generation's migration choice and the child generation's income, whereas we investigate the education history and the labour market experience of the same generation. In addition, while Lyu and Chen (2019) demonstrate the correlation between the length of education and labour market returns, we focus on the wage impact of different educational trajectories, a research direction that has less conclusive empirical support to date. Therefore, this paper endeavours to form a constructive dialogue with the rising academic attention cast upon an ever more diversified population of young migrants.

Moreover, while insights into China-specific policy, for example, the hukou system, would certainly inform us about the institutional backdrop of migrant employment in cities, the comparative political economy literature might lend us a new perspective. The 'variety of capitalism' literature argues that in the context of global competition, the institutions, policies and regulations of a particular economy often coordinate to form 'institutional complementarity', a concept in which the formative parts of the institutional establishment in an economy share an internal logic, thereby complementing and reinforcing one another (Hall and Soskice 2001; Höpner 2005). More specifically, education systems would serve to support the specific labour market needs of a place, and the labour markets 
would return sufficient rewards to graduates of local schools. For instance, London, a leading European city in a service-prone economy, is buttressed by an education system that equips the labour force with highly transferable general skills, whereas in manufacturing-focused German cities, such as Stuttgart, we find the prevalence of apprenticeships that lead to the formation of highly specific engineering skills (Alessandrini et al. 2017; Durazzi 2018). Since a skillset gained in the receiving country or city often accords with the needs of local industries, it is often easier to convert it to an 'education reward'. In contrast, immigrants or domestic migrants who studied elsewhere might find that their skillsets do not match the labour market needs of the receiving places, thereby imposing an education penalty.

Regional studies demonstrate that China has a variety of subnational production regimes. Such prototypical regimes include the Guangdong Model, the Sunan Model, the Wenzhou Model, the Zhongguancun Model and the Chongqing model. These cities or city clusters have developed skill-formation strategies corresponding to the unique needs of their local labour markets. For instance, the technology-light, labour-intensive, and export-oriented Guangdong model offers a paucity of training opportunities for low-skilled migrant workers; in contrast, the Sunan city cluster, as a national and international hub for the information technology industry, has built an education system that offers relatively substantial training opportunities to migrant workers (Zhang and Peck 2016). Consequently, migrants who obtain sector-specific education or training in the Sunan region find it relatively easy to obtain a decent wage (Li 2019; Wang 2006).

Evidence shows that city governments in China enjoy a high level of autonomy to devise development strategies that are most suitable for local conditions to succeed in domestic and international competitions (Wu and Zhang 2007). With regard to educational policy, while the central government exerts tight control over moral and ideological education, it encourages local educational authorities to devise their own curricula in practical disciplines to better reflect regional socioeconomic realities (Feng 2006; Huang et al. 2015). Such is especially the case for vocational education, as its primary purpose is to supply capable workers to facilitate local economic development. As a result, local education systems are able to complement local production regimes. However, the regionally variegated production regimes in China also highlight the possibility of an educational penalty when domestic migrants move to work in a place other than where they received their education.

While the majority of young migrants move to cities after receiving a formal education in search of better job opportunities, an increasing number among them migrated to cities as dependent children of their parents, who are the 'first-generation migrant workers'. In other words, an assignable proportion of the new-generation migrant workers received their education from public or private institutions in receiving cities, where they had the opportunity to acquire skills matching local production regimes, learn local dialects, and accumulate social capital (Dustmann and Fabbri 2003; Wang and Fan 2012). Therefore, this paper first aims to investigate whether there are wage gaps among these new-generation migrant workers. Specifically, we hope to examine whether attending schools in receiving cities leads to higher labour market returns. 
This paper also aims to explore the impact of different tracks of senior-secondary education on income. According to human capital theorists (Becker 1962), specific skills accumulated through vocational education are associated with better performance in the labour market, as such skills better accommodate the needs of employers. Nevertheless, a contending group of theorists argues that general skills acquired through academic education better demonstrate the learning potential and intellectual capacities of job applicants to employers; thus, students pursuing academic tracks are likely to outperform competitors from vocational tracks (Spence 1974). Hence, we will engage with this long-standing debate and examine whether the vocational route of senior-secondary education leads to higher salaries for young Chinese migrants than those brought by the academic route.

If young migrants with different educational backgrounds indeed experience distinctive labour market returns, then this paper further explores whether their choices of job industry and occupation played a mediating role in deciding the intragroup wage heterogeneity - the key mechanism accounting for the wage gap between migrant and indigenous workers in urban China.

This paper proceeds as follows: it first elaborates the theoretical framework and hypotheses; it then discusses the data and methodology, followed by reporting the empirical results from the data analysis. This paper concludes with a brief discussion and a vision for future academic exploration.

\section{Theories and hypotheses}

\subsection{Education location and labour market returns}

In explaining wage income, Mincer (1974) acknowledged the determining influences of educational background and work experience. He modelled them as a function of years of schooling and years of work experience. More recent empirical studies also find that the length of education is the main cause of wage differences between indigenous and migrant workers, as well as among migrant workers themselves (Démurger et al. 2009).

However, measuring education only by its length overlooks its qualitative attributes. Evidence shows that the qualitative attributes of education strongly correlate with graduates' income levels, even when they receive the same years of schooling (Strayer 2012). Moreover, as discussed above, the location of education implies the compatibility between students' skills and employers' needs. Thus, it is reasonable to expect that attending schools in receiving cities would offer migrant workers comparative advantages in the labour market compared with peer migrants who have been educated elsewhere. For migrants educated elsewhere, while a small proportion of them moved from urban hometowns to a new receiving city, the majority moved from rural to urban areas. However, we do not distinguish whether they were educated in rural or urban settings, although the former would certainly be more common, as the emphasis is on local versus elsewhere. This paper tries to nuance the Mincer function by innovatively incorporating the education location and testing the following hypothesis: 
H1 Migrant workers who received senior-secondary education ${ }^{1}$ in receiving cities earn higher wages than their counterparts who received senior-secondary education elsewhere.

\subsection{Educational tracks and skill formation}

In addition to the education location, the education track is also an important qualitative attribute that we consider. There is a long-standing debate on the comparison of the labour market returns of different educational tracks between scholars who subscribe to human capital theory and those who subscribe to signalling theory. Becker (1994) distinguished two different types of skills. While general skills refer to general knowledge or cognitive abilities that students acquire from academic education, specific skills concern specific occupational competences that students primarily gain through vocational education or training (Müller 2005, p. 464). Human capital theorists argue that the human capital accumulated through vocational education is directly related to the workplace and is readily tradable in the labour market; by contrast, general skills obtained from academic curricula are relatively detached from the labour market and thus less economically valuable (Côté 2014).

The contending signalling theory argues that employers face practical difficulties in assessing job seekers' human capital or specific skills and are therefore unable to predict their future productive capacity (Spence 1974). According to Shavit and Müller (2000), holding a vocational certificate might appear as a signal of the applicant's low cognitive ability or even being a 'troublemaker' since a capable student would always choose the academic education track. Hence, the signalling theory predicts higher labour market returns for academic credentials over vocational ones.

Both human capital theory and signalling theory have received some degree of support in empirical studies (Müller 2005; Shavit and Müller 2000). With a sample size of more than 60,000 , we try to engage with the academic debate between the two groups of theorists using evidence from young migrants in urban China. We hypothesise the following:

H2 Migrant workers who chose the vocational track in their senior-secondary education earn higher wages than their counterparts from the academic track.

\subsection{Industrial/occupational distribution as a mediator}

As we discussed in the introduction, when explaining migrant workers' lower income compared to that of indigenous workers at the same educational level, scholars show this discrepancy is because migrants are often not eligible to take up certain well-paid occupations or enter some high-income industries (Zhang et al. 2007). For instance, Tian (2010) found that $61.2 \%$ of migrant workers' wage disadvantage

\footnotetext{
${ }^{1}$ Refer to Sect. 3.1 Research methods: Data and sample for the rationale behind focusing on migrants whose level of education is senior-secondary.
} 
could be explained by the industrial (occupational) segregation between migrant and indigenous workers.

Since industrial/occupational segregation is the main mechanism causing wage differences between indigenous and migrant workers, we hope to explore whether the same mechanism might explain the intragroup wage difference, if any, among young migrants. The previous immigration literature suggests that second-generation immigrants who received senior-secondary education in Germany were able to break the occupational segregation between immigrants and local workers (Kogan 2004). Other studies demonstrate that language acquisition through formal education in receiving countries contributes to the upward occupational mobility of immigrants (Berman et al. 2003; Dustmann and Fabbri 2003). The literature focusing on China shows that domestic migrants who attended schools in receiving cities are likely to conform to the working values of local people. Whereas indigenous workers often avoid the so-called 'inferior' industries and occupations that are 'dirty, tiring, and dangerous' (Liu and Chen 2008, p. 51), first-generation migrant workers are willing to enter such industries. Unlike their parents, however, many new-generation migrants, who receive education in receiving cities and stay in the urban environment for a long time, have a good chance of adopting the working values of indigenous workers and thus also prefer to avoid the 'inferior' industries and occupations (Tian 2013). Therefore, it is reasonable to posit the following:

H3 Young migrant workers following different trajectories of senior-secondary education are likely to have different choices of job industries and occupations, which mediates the effects of educational trajectories on wages.

\section{Research methods}

\subsection{Data and sample}

This paper uses the data collected through the National Migrant Dynamics Monitoring Survey (NMDMS) in China. This survey was administered by the former National Population and Family Planning Commission (NPFPC) and its subsequent National Health and Family Planning Commission (NHFPC) and National Health Commission (NHC). It is conducted annually from 2010 to 2018. This survey offers the first open dataset focusing on domestic migrant workers in receiving cities in China. Although its main purpose is to investigate migrant workers' access to healthcare and family planning services in receiving cities, it also collects information about migrant workers' education, employment, socioeconomic status, social integration and access to social welfare in receiving cities. This paper uses the 2010-2013 waves of the survey to form a cross-sectional dataset since these waves contain information on young migrants' education at the senior-secondary level. In total, we obtain a sample size of 60,658 .

Although the survey was not purposefully designed for educational research, this dataset is arguably the best available option to study our topic. As the national census and most large-scale surveys are targeted at residents, most of whom are 
indigenous, it is very difficult to identify migrants. Due to their unstable working and living patterns, migrant people are systematically underrepresented in censuses and other themed surveys (Li 1999). Remarkably, the NMDMS is specifically targeted at migrants, and the Probability Proportional to Size (PPS) sampling method employed by the survey ensures its representativeness.

Notably, our dataset only includes young migrants whose education level is senior-secondary. The reason is twofold: First, it is relatively easy to gain a settled status, or a local hukou, if the migrant has a tertiary education credential. Therefore, he or she would naturally disappear from the survey dataset. Second, there is no distinct vocational education offered at the junior-secondary level or below. Since we aim to examine the impacts of the location and track (rather than length) of education on wage income, it is justifiable to draw comparisons within the same level of seniorsecondary education.

\subsection{Variables and measurement}

The dependent variable of this study is individual young migrants' monthly income. Since our sample was taken from four consecutive years of the NMDMS data (i.e., from the 2010 survey to the 2013 survey), we have re-evaluated migrants' incomes into constant 2010 prices using the Consumer Price Index published by the National Bureau of Statistics. The natural logarithm of the inflation-adjusted monthly income will be taken as our dependent variable in regression analyses.

The two independent variables of this study are young migrants'senior-secondary education location and senior-secondary education track. Together, they capture young migrants' trajectories of senior-secondary education. The senior-secondary education location is coded as a dummy variable (receiving city $=1$ ), as is the senior-secondary education track (vocational track $=1$ ).

Notably, as the survey did not ask directly where the respondents received their senior-secondary education, we have to reconstruct the senior-secondary education location variable with information on the timing of flows into current receiving cities. Respondents with senior-secondary education level are considered to have attended high schools in the current receiving cities if they moved to the current receiving cities at or before the age of 15-the lowest entrance age for senior-secondary schools in China. ${ }^{2,3}$ Respondents with senior-secondary education level who

\footnotetext{
2 The questionnaire asks respondents about their current migration experience. If they flowed into the current receiving city $\mathrm{A}$ at the age of 15 , they should not have been away from city $\mathrm{A}$ for more than 6 months since then. This is because, if they left city A and returned later, the later time point would be recorded in the interview. Hence, for respondents who moved to the current receiving cities at or before the age of 15 , their education location of senior-secondary education should be the current receiving cities.

3 Noted that the standard senior-high school entry age (i.e. age 15) may not be always applicable, especially in some rural areas where delayed graduation from junior-high school is common. Thus, migrants' hukou type (i.e. rural hukou or urban hukou) is taken as a proxy to control for the urban-rural difference in the age of senior-high school entry. Hukou location is not used as a proxy in this regard, as the survey only asks respondents about the province to which their hukou belongs, which is not specific enough to account for the potential urban-rural difference in the age of senior-high school entry.
} 
arrived in receiving cities after age 15 are deemed to have attended high schools elsewhere.

In other words, this paper does not consider the situation of transfer students who first attended high schools elsewhere at the age of 15, then moved to receiving cities and continued studying at the age of 16 or 17 . One reason for this decision is that transfer at the senior-secondary education stage is normally prohibited (Ni 2010). For high-school students who migrated at the age of 16 or 17, the most likely scenario is that they would leave school at the same time and prematurely enter the labour market in their receiving city. As long as they have attended high school for at least 1 year, we still count them as having been educated at the senior-secondary level, in line with the Chinese national census definition. It is worth reiterating that the length of schooling is included in the Mincer function as an independent variable. However, this paper focuses on migrant workers at the same education level, so this variable is naturally controlled.

Two potential mediating variables are examined in this study, including job industry and occupation type. We follow Xie's (2012) classification standard and merge detailed industry and occupation types into more general categories. With regard to the job industry, six general categories are distinguished: primary industries (agriculture, forestry, animal husbandry and fisheries), secondary industries (manufacturing, mining and construction), tertiary industries-category 1 (transportation, communications, real estate and financial services), tertiary industries-category 2 (wholesale and retail, catering and accommodation), tertiary industries-category 3 (public services and education, science, culture and health-related industries), and other unclassified industries. Concerning respondents' occupation types, we classify them into seven categories: government officials and social managers (I), professionals (II), clerical support workers (III), commerce and service workers (IV), agricultural/forestry/fishery workers (V), production/transport workers and related personnel (VI), and other unclassified occupations (VII).

The control variables included in regression analyses are migrants' age (and its square term), local work experience (and its square term), gender (male $=0$; female $=1)$, hukou type (rural =0; urban=1), the provincial dummies of receiving cities and the year of survey (categorical variable).

According to Mincerian convention, total work experience, as measured by the sum of past employed years (Saha and Sarkar 1999), should be included as a control variable. As we give theoretical weight to the education and experience acquired in current receiving cities, we include local work experience in addition to age to capture the former's additive wage effects. For respondents educated in receiving cities, their local work experience is a continuous variable approximated by the difference between their age at the time of survey and 18, that is, the age when they are expected to complete senior-secondary education. Our rationale is that if a migrant student was able to enrol in a high school in the receiving city, it would be irrational to terminate his or her studies before obtaining a degree certificate. Therefore, we assume that he or she would enter the labour market at age 18. For respondents educated elsewhere, their local work experience is measured by the difference between the year of survey and the year in which the respondents flowed into the current receiving cities. 
A young migrant's hukou type (i.e. rural or urban hukou) is included as a control for the potential urban-rural heterogeneities in factors such as the normal age of senior-high school entry, which may affect the precision of our measure for migrants' senior-secondary education location (for details, see note 3). Likewise, the provincial dummies of receiving cities ${ }^{4}$ are also controlled to capture provincial differences in industrial and labour-market structures that may affect the labour market returns to education.

\subsection{Model and analytical strategies}

To examine the labour market returns for different trajectories of senior-secondary education, we specify our baseline model as a fixed-effects linear model:

$$
\ln \mathrm{W}_{i j}=\beta_{0}+\beta_{1} \text { EduTrack }_{i j}+\beta_{2} \text { EduLocation }_{i j}+\delta x_{i j}+\alpha_{i}+\varepsilon_{i j}
$$

Specifically, $\ln \mathrm{W}_{i j}$ is the natural logarithm of the inflation-adjusted monthly income of individual migrant $j$ currently working in province $i$, which is the dependent variable. EduTrack ${ }_{i j}$ and EduLocation E $_{i j}$ represent the track and the location of senior-secondary education, respectively, which are the two independent variables that capture a migrant's trajectory of senior-secondary education. $\mathrm{x}_{i j}$ stands for the set of control variables of this study. $\alpha_{i}$ represents the fixed effect of province $i$ and $\varepsilon_{i j}$ is the residual term.

Based on the above model, we will conduct multiple regression analyses with the estimation method of ordinary least squares (OLS). Specifically, robust standard errors are adopted in this paper to take into account the potential heteroscedasticity issue so as to obtain unbiased standard errors of the OLS coefficients.

To further investigate whether and the extent to which the effects of educational trajectories on wage income are mediated by young migrants' job industry or occupation, we will add job industry and occupation type, respectively, to the baseline model and employ Sobel-Goodman mediation tests (Goodman 1960; Sobel 1986) to evaluate if the respective mediating effects of job industry and occupation are of statistical significance.

\section{Results}

\subsection{Descriptive findings}

The descriptive statistics for the variables included in our regression analyses are shown in "Appendix A". In particular, concerning the distribution of the two independent variables (as shown in Table 1), we find that young migrants are not evenly

\footnotetext{
${ }^{4}$ In light of Xie (2012) and Lyu and Chen (2019), we appreciate the value of controlling for the dummies of receiving cities (municipality/prefecture-level or below). However, in the 2010 survey data, the receiving cities are coded in a particular numerical scheme, which is not disclosed in the dataset or the technical document. So, we have opted for controlling the province to which the receiving city belongs.
} 
Table 1 Frequency (percentage) distribution and mean income of young migrants by senior-secondary education trajectory

\begin{tabular}{llll}
\hline $\begin{array}{l}\text { Senior-secondary education } \\
\text { location }\end{array}$ & \multicolumn{2}{l}{ Senior-secondary education track } & Total \\
\cline { 2 - 3 } & Vocational track & Academic track & \\
\hline Receiving cities & $705(1.2 \%)$ & $1360(2.2 \%)$ & $2065(3.4 \%)$ \\
Mean income (yuan) & 2016.05 & 2248.60 & 2169.20 \\
Other locations & $20,613(34.0 \%)$ & $38,007(62.6 \%)$ & $58,620(96.6 \%)$ \\
Mean income (yuan) & 2537.20 & 2710.96 & 2649.86 \\
Total & $21,318(35.1 \%)$ & $39,367(64.9 \%)$ & $60,685(100 \%)$ \\
Mean income (yuan) & 2519.96 & 2694.98 & 2633.50 \\
\hline
\end{tabular}

distributed along the tracks and locations of senior-secondary education. While $35.1 \%$ of young migrants attended vocational high schools, $64.9 \%$ of them received education from academic schools. The majority of migrants $(96.6 \%)$ attended high school elsewhere and migrated to the current city afterwards; nevertheless, approximately $3.4 \%$ of migrants (i.e., a small group of 2065 people) were educated in the current receiving cities.

By cross-tabulating the two independent variables, we can categorise young migrants into four groups according to their senior-secondary education trajectories. We contend that the seemingly skewed distribution of young migrants with different education trajectories does not result from sampling bias but is representative of the situation in the population. For example, the trajectory type (receiving vocational education in the current receiving cities) with the smallest sample size nevertheless has 705 cases.

The mean income of young migrants by senior-secondary education location and track is also shown in Table 1. Young migrants educated in academic high schools earned, on average, 175 yuan more than their counterparts who attended vocational schools per month. The comparison of young migrants educated in receiving cities and those educated elsewhere yields a much starker contrast: young migrants educated elsewhere earned 481 yuan more than their counterparts educated in the current receiving cities per month. If these two factors are considered simultaneously, young migrants educated in vocational high schools in the current receiving cities had the lowest monthly income (2016 yuan), whereas those who took the academic track in other locations had the highest income (2711 yuan).

The descriptive findings appear to be contradictory to H1 and H2. First, attending high school in receiving cities, where the education system is supposed to be better coordinated with local production regimes, did not bring young migrants higher economic returns in the labour market. Second, choosing the vocational track in their senior-secondary education did not help transform specific skills into higher labour market returns. By contrast, the academic track that equips young migrants with general skills was better rewarded in the labour market.

To further explore whether the aforementioned wage variations among migrants with different educational trajectories can be explained by the different choices of job industries or occupations, we will first present the percentage frequency distribution of young migrants' job industry and occupation by their 
Table 2 Distribution of young migrants' job industry and occupation by senior-secondary education trajectory

\begin{tabular}{|c|c|c|c|c|}
\hline & \multicolumn{2}{|c|}{ Education location } & \multicolumn{2}{|l|}{ Education track } \\
\hline & $\begin{array}{l}\text { Receiving } \\
\text { cities (\%) }\end{array}$ & Other locations (\%) & Vocational (\%) & Academic $(\%)$ \\
\hline \multicolumn{5}{|l|}{ Industry } \\
\hline Primary industries & 2.47 & $0.56 * * *$ & 0.61 & 0.63 \\
\hline Secondary industries & 21.16 & $31.15^{* * *}$ & 36.45 & $27.76 * * *$ \\
\hline Tertiary industries-Category 1 & 5.96 & 5.75 & 5.75 & 5.75 \\
\hline Tertiary industries-Category 2 & 38.64 & 37.26 & 31.15 & $40.64 * * *$ \\
\hline Tertiary industries-Category 3 & 21.84 & $18.21 * * *$ & 19.27 & $17.83 * * *$ \\
\hline Other & 9.93 & $7.07 * * *$ & 6.76 & $7.38 * *$ \\
\hline \multicolumn{5}{|l|}{ Occupation } \\
\hline $\begin{array}{l}\text { Government officials and social } \\
\text { managers }\end{array}$ & 0.39 & 0.31 & 0.36 & 0.29 \\
\hline Professionals & 8.43 & 9.63 & 13.35 & $7.55^{* * *}$ \\
\hline Clerical support workers & 2.71 & 2.85 & 3.76 & $2.35 * * *$ \\
\hline Commerce and service workers & 63 & $59.15^{* * * *}$ & 51.73 & $63.38 * * *$ \\
\hline $\begin{array}{l}\text { Agricultural, forestry and fishery } \\
\text { workers }\end{array}$ & 2.18 & $0.46 * * *$ & 0.46 & 0.55 \\
\hline Production/transport workers & 18.01 & $24.64 * * *$ & 27.46 & $22.77 * * *$ \\
\hline Other & 5.28 & $2.96 * * *$ & 2.89 & 3.12 \\
\hline
\end{tabular}

$* p<.05 ; * * p<.01 ; * * * p<0.001$

senior-secondary education trajectories in Table 2. If there were significant intragroup differences in the industrial and occupational distribution, we would further investigate whether job industry and occupation mediate the effects of education on wages.

In terms of young migrants' industrial distribution, we find a significantly higher percentage $(31.15 \%)$ of young migrants educated elsewhere concentrating in the secondary industries (i.e., manufacturing, mining and construction) compared with their counterparts educated in receiving cities (21.16\%). By contrast, the latter group was significantly more likely to take up jobs in the primary industries (i.e., agriculture, forestry, animal husbandry and fisheries), category 3 tertiary industries (i.e., public services and education, science, culture and health-related industries) and other unclassified industries. In the comparison between migrants from the academic and vocational tracks, a significantly higher percentage of young migrants from the vocational track were working in the secondary industries and category 3 tertiary industries. In contrast, young migrants from the academic track were significantly more likely to work in category 2 tertiary industries (i.e., wholesale and retail, catering and accommodation) and other unclassified industries. The group differences were most prominent in the secondary industries ( $8.69 \%$ difference) and category 2 tertiary industries (9.49\% difference).

With regard to the occupational distribution of migrants educated in different locations, we find that, compared with their counterparts educated in receiving 
cities, a higher percentage of young migrants educated in other locations worked as production/transport workers and related personnel, which accounts for the largest group difference among all occupations. Those educated in receiving cities had a higher chance of working as commerce and service workers; agricultural, forestry and fishery workers; or workers in other undefined occupations. Migrants from different educational tracks displayed differences as well, i.e., graduates of academic high schools were significantly more likely to work as commerce and service workers but were significantly less likely to work as professionals, clerical support workers and production/transportation workers.

In summary, we find a significant, uneven distribution of job industries and occupations among young migrants following different educational trajectories. Specifically, young migrants educated in receiving cities were less likely to engage in secondary industries or to work as production and transportation workers. As these are relatively dirtier, more tiring and more dangerous jobs that indigenous workers usually avoid, this trend lends support to the received wisdom that young migrants educated in receiving cities might have adapted to the working values of the indigenous population and deliberately avoided these 'inferior' jobs (Liu and Chen 2008; Tian 2013). These findings offer preliminary support for $\mathrm{H} 3$ and leave us to investigate whether such patterns have mediating effects on their wages.

\subsection{Regression analyses}

In Table 3, we report the regression results. In the baseline model (Model 1), apart from the control variables, we include only the track and the location of seniorsecondary education to estimate their main effects. All the predictors reached statistical significance at $p<.001$, with the exception of the education track $(p<.05)$. With other factors controlled, young migrants from the academic track earned $1.0 \%$ $\left(=\mathrm{e}^{0.01}-1\right)$ more than their counterparts educated through vocational high schools. By comparison, the income difference between young migrants educated in receiving cities and other locations was even larger, with migrants educated in receiving cities earning $8.3 \%\left(=\mathrm{e}^{0.08}-1\right)$ less than their counterparts educated elsewhere.

Therefore, our findings reject the human capital hypothesis (H2) and lend support to the contending signalling theory hypothesis. Our findings indicate that employers are paying more for general knowledge than for specific skills. These results echo the literature on the stigmatisation of attending vocational schools and the higher social acceptance of academic education (Klorer and Stepan 2015). Other contributing factors might include the low quality of vocational education, as well as the mismatch between skills formed in vocational schools and the needs of labour markets, as suggested by the existing literature (Li and Yuan 2016; Bin and Xu 2017; Zhang 2015). ${ }^{5}$ Moreover, we reject $\mathrm{H} 1$, which predicted that young migrants educated in

\footnotetext{
5 Noted that this "mis-match" thesis does not offer a satisfactory explanation for the wage disadvantage of migrants receiving vocational education in current receiving cities, as one can hardly expect skillsformation elsewhere better caters for the labour market needs of City A than City A's own vocationaleducation system. So, we consider the mismatch between skills and labour market needs as a secondary explanation for the wage variation between migrants following different educational tracks.
} 


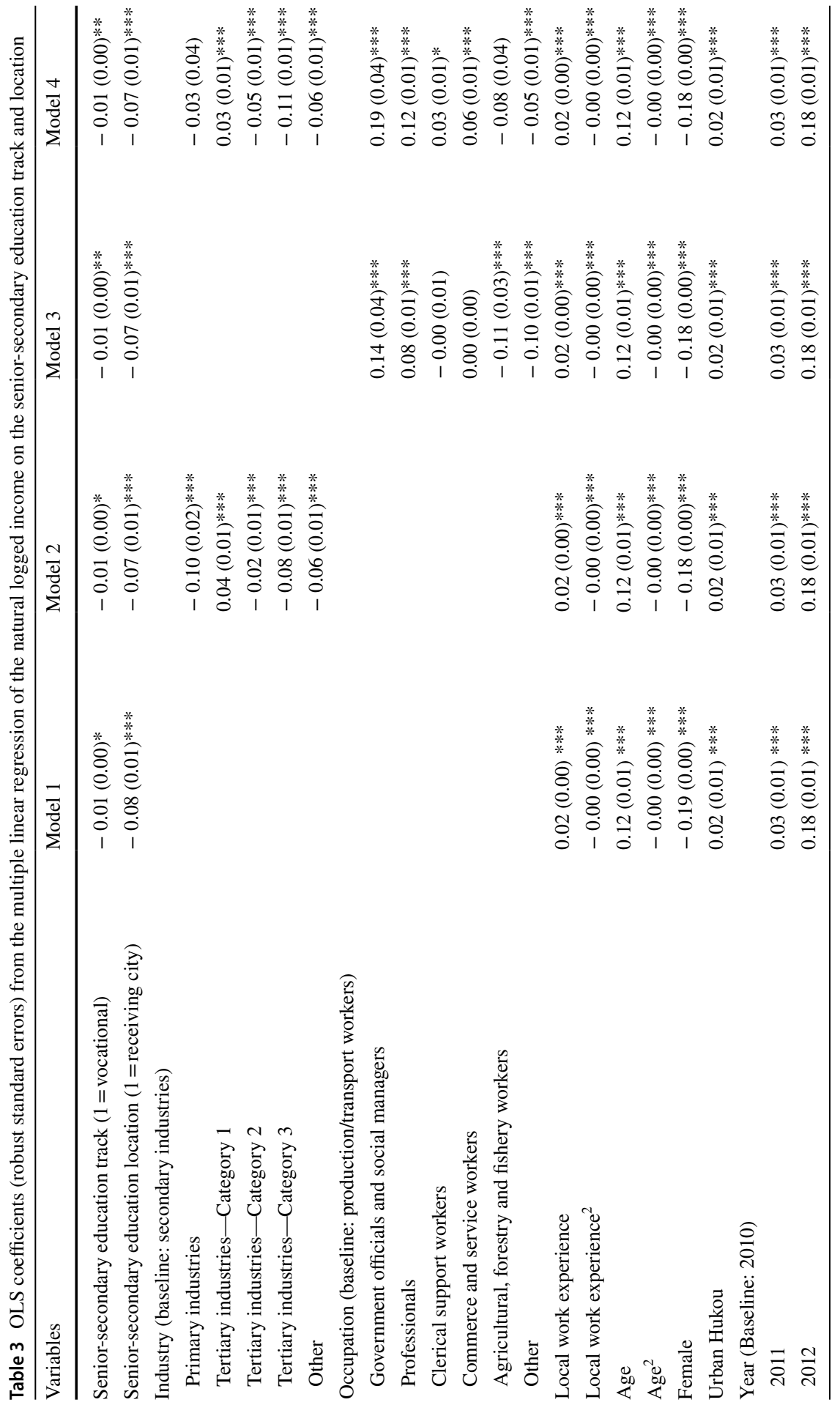




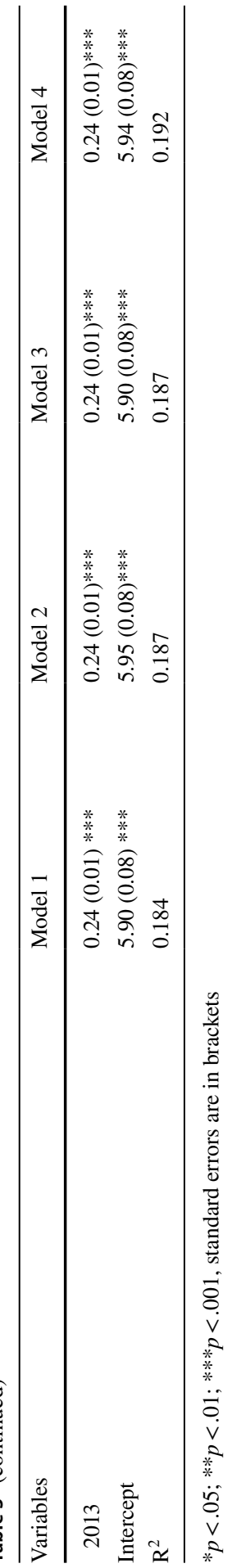


Table 4 Sobel-Goodman test for the mediation effect of job industry and occupation

\begin{tabular}{|c|c|c|c|c|}
\hline \multirow[t]{3}{*}{ Mediator } & \multicolumn{2}{|c|}{ Senior-secondary education location } & \multicolumn{2}{|c|}{$\begin{array}{l}\text { Senior-secondary education } \\
\text { track }\end{array}$} \\
\hline & \multicolumn{2}{|c|}{ Receiving cities (vs. other locations) } & \multicolumn{2}{|c|}{$\begin{array}{l}\text { Vocational track (vs. aca- } \\
\text { demic track) }\end{array}$} \\
\hline & Mediation effect & $\begin{array}{l}\text { Mediation effect/total } \\
\text { effect }(\%)\end{array}$ & $\begin{array}{l}\text { Mediation } \\
\text { effect }\end{array}$ & $\begin{array}{l}\text { Mediation } \\
\text { effect/total } \\
\text { effect }\end{array}$ \\
\hline Job Industries & $-0.005^{* * *}$ & 5.8 & $\mathrm{n} / \mathrm{a}$ & $\mathrm{n} / \mathrm{a}$ \\
\hline Occupational types & $-0.004 * * *$ & 5.5 & $\mathrm{n} / \mathrm{a}$ & $\mathrm{n} / \mathrm{a}$ \\
\hline $\begin{array}{l}\text { Job industry }+ \text { occupa- } \\
\text { tional types }\end{array}$ & $-0.006^{* * *}$ & 7.5 & $\mathrm{n} / \mathrm{a}$ & $\mathrm{n} / \mathrm{a}$ \\
\hline
\end{tabular}

$* p<.05 ; * * p<.01 ; * * * p<0.001 ; \mathrm{n} / \mathrm{a}$ stands for not applicable, meaning job industry and occupation type do not mediate the effects of education track on income

receiving cities would earn more than their counterparts. The unexpected wage disadvantage of being educated in receiving cities propels us to further explore potential causal mechanisms.

Concerning the control variables, the rate of return to age, which reflects young migrants' total work experience, was approximately $12.7 \%\left(=\mathrm{e}^{0.12}-1\right)$ per year. On this basis, every extra year of local work experience would increase young migrants' income by $2.0 \%\left(=\mathrm{e}^{0.02}-1\right)$. Moreover, we find a severe gender inequality in income among young migrants. With other things being equal, male migrant workers enjoyed as much as a $20.9 \%\left(=\mathrm{e}^{0.19}-1\right)$ advantage over women in earnings. In addition, young migrants' hukou type constitutes another source of income heterogeneity. For those holding rural hukou, their earnings were $2.0 \%\left(=\mathrm{e}^{0.02}-1\right)$ lower than those of young migrants with urban hukou. Finally, since young migrants' income has been re-evaluated into constant prices, the ascending coefficients of the year dummies suggest that young migrants' incomes were growing, by varying degrees, each year.

To further examine whether the explanatory power of educational trajectories on income is mediated by young migrants' choice of job industries and occupations, we will add, on top of the baseline model, job industry to Model 2 and occupation type to Model 3 and employ Sobel-Goodman mediation tests (see Table 4) to evaluate their respective mediating effects.

From Model 2, we find that, compared with those working in the secondary industries, young migrants received lower earnings in all other industries except category 1 tertiary industries. According to the descriptive analyses (see Table 2), while young migrants following all educational trajectories showed no difference in the proportion of people working for the best-paid industries (i.e., category 1 tertiary industries), they showed noticeable intragroup differences in entering the second best-paid industries (i.e., secondary industries). Compared to their respective counterparts, there were a significantly higher proportion of elsewhere-educated or vocational-track young migrants working for secondary industries. 
Can the comparative income advantage of young migrants educated elsewhere be explained by a higher proportion of them working for well-paid secondary industries? Our Sobel-Goodman mediation test (see Table 4) suggests that 5.8\% of the total effect of education location on income was mediated by young migrants' patterns of concentration in job industries, and this mediating effect of job industry is statistically significant at the 0.001 level.

Nevertheless, a higher percentage of vocational school graduates working in well-paid secondary industries could not explain their lower wages, which is also indicated by a lack of change in the coefficient of educational track in Model 2 after job industry is added to the baseline model. In short, the job industry mediates the effects of educational location on income but not the effects of educational track on income.

In Model 3, we obtain the effects of job occupation on young migrants' earnings. We have chosen production/transport (VI) workers as the baseline occupation category in the regression, as it accounted for the largest difference between young migrants educated in different locations. Compared to this baseline category, young migrants would earn significantly higher incomes if they worked as government officials/social managers (I) and professionals (II). However, if they worked as agricultural/forestry/fishery workers (V) or in other unclassified occupations (VII), their incomes would be significantly lower.

As shown in Table 2, young migrants educated in different locations were similarly unlikely to take up the best-paid occupations (including government officials/ social managers and professionals). Nevertheless, while migrants educated elsewhere were more likely to work as middle-income production or transport workers, migrants educated in receiving cities were much more prone to entering lower-paid occupations (i.e., agricultural/forestry/fishery workers and other unclassified occupations). In other words, the income advantage of the former group can be partially explained by a higher proportion of them taking up the occupations bringing medium-high income. The Sobel-Goodman mediation test (see Table 4) further confirms that the mediating effect of occupation accounts for $5.5 \%$ of the total effect of education location on income, which is statistically significant at the 0.001 level. Nevertheless, we believe the effect of educational track on income was not mediated by young migrants' occupational choice because vocational school graduates, in contrast to their disadvantages in earnings, were actually more likely to take up better-paid occupations.

In Model 2 and Model 3, we added job industry and occupation type separately to the baseline model to avoid the potential problem of multicollinearity since job industry and occupation type are hardly independent from each other. After estimating their respective mediating effects in Model 2 and Model 3, we now include both variables in Model 4 to estimate their aggregate mediating power.

In Model 4, we find a slight increase in the standard errors of the job industry and occupation type variables, which results in a loss of statistical significance in certain categories of these two variables. Nevertheless, the positivity/negativity of their coefficients remains almost unchanged. The Sobel-Goodman mediation test (see Table 4) suggests that the aggregate mediating effect of job industry and occupation 
is statistically significant at the 0.001 level, mediating $7.5 \%$ of the total effect of education location on income. Notably, this aggregate mediating effect of $7.5 \%$ is smaller than the sum of the respective mediating effects of job industry (5.8\%) and occupation (5.5\%), which is largely due to the correlation between job industry and occupation. Again, there is no change in the coefficient of educational track, and we conclude that job industry and occupation do not mediate the total effect of education track on income.

\section{Conclusion and discussion}

As a growing number of urban studies researchers cast their eyes on the wage differences between indigenous and migrant workers in Chinese cities, this paper offers a telescopic lens through which to observe heterogeneity within the group of migrant workers. This paper studies the impact of education track and location during senior-secondary education on wage. We hope to form a dialogue with other empirical studies evidencing the importance of education length on income. This paper argues for the theoretical importance of modelling the qualitative attributes of education in terms of its track and location.

Apart from highlighting the stark heterogeneity in wage income among migrant workers from different educational trajectories, this paper further tests the mediating effects of job industry and occupation with the Sobel-Goodman method. While we are confident about the ability of the selected mediators to explain the wage difference between migrant groups educated in different locations, it cannot explain the wage difference between migrant groups who followed different education tracks. The wage disadvantage of a vocational school graduate might be due to the low degree of social acceptance. Although testing the underlying causal mechanisms is beyond the scope of our data but is firmly on our future research agenda. Moreover, it is not entirely clear why different migrant groups present different patterns of industrial and occupational concentration. The thesis of value acquisition might be a promising hypothesis. Some in-depth interviews with young migrants might help us understand whether distinctive working values have indeed driven them to behave differently in choosing their job industry and occupation.

As we have seen in some successful global cities, concerted educational systems and labour markets would help cities to maximise the comparative advantages of their production regimes. We expected to see that Chinese domestic migrants educated in receiving cities would be able to break the industry and occupation ceilings and earn more. If education in current receiving cities fails to translate into an income incentive for migrant workers, there is a possibility that young migrants possessing the skills needed most by local employers would be reluctant to settle in. Now that we have discovered the impact of disconcerted education and labour market policies on income variations at the individual level, we will seek, in future research, to understand how such discrepancies might affect the upgrading of regional production regimes in China. 


\section{Appendix A}

See the Table 5 .

Table 5 Descriptive statistics for variables included in regression analysis

\begin{tabular}{|c|c|}
\hline Variable & Mean (SD) \\
\hline \multicolumn{2}{|l|}{ Dependent variable } \\
\hline \multicolumn{2}{|l|}{ Monthly income (adjusted for inflation) } \\
\hline In Yuan & $2633.501(3405.26)$ \\
\hline Natural logged & $7.703(0.53)$ \\
\hline \multicolumn{2}{|l|}{ Independent variables } \\
\hline Senior-secondary education track $(1=$ vocational $)$ & $0.351(0.48)$ \\
\hline Senior-secondary education location ( $1=$ receiving city $)$ & $0.034(0.18)$ \\
\hline \multicolumn{2}{|l|}{ Mediating variables } \\
\hline \multicolumn{2}{|l|}{ Industry } \\
\hline Primary industries & 0.006 \\
\hline Secondary industries & $0.308(0.46)$ \\
\hline Tertiary industries-Category 1 & $0.058(0.23)$ \\
\hline Tertiary industries-Category 2 & $0.373(0.48)$ \\
\hline Tertiary industries-Category 3 & $0.183(0.39)$ \\
\hline Other & $0.072(0.26)$ \\
\hline \multicolumn{2}{|l|}{ Occupation } \\
\hline Government officials and social managers & 0.003 \\
\hline Professionals & $0.096(0.29)$ \\
\hline Clerical support workers & $0.028(0.17)$ \\
\hline Commerce and service workers & $0.593(0.49)$ \\
\hline Agricultural, forestry and fishery workers & $0.005(0.07)$ \\
\hline Production/transport workers and related personnel & $0.244(0.43)$ \\
\hline Other & $0.030(0.17)$ \\
\hline \multicolumn{2}{|l|}{ Control variables } \\
\hline Local work experience & $2.539(2.60)$ \\
\hline Local work experience ${ }^{2}$ & $13.216(26.48)$ \\
\hline Age & $25.283(3.98)$ \\
\hline $\mathrm{Age}^{2}$ & $655.084(202.06)$ \\
\hline Female & $0.454(0.50)$ \\
\hline Urban Hukou & $0.169(0.38)$ \\
\hline \multicolumn{2}{|l|}{ Year } \\
\hline 2010 & 0.186 \\
\hline 2011 & $0.147(0.35)$ \\
\hline 2012 & $0.287(0.45)$ \\
\hline 2013 & $0.380(0.49)$ \\
\hline
\end{tabular}

$\mathrm{N}=60,685$ 
Acknowledgements We would like to thank the National Health Commission of China for granting us the access and usage of the National Dynamic Monitoring Survey of Migrant Population Data.

Funding No funding was received for conducting this study.

Data availability The data that support the findings of this study are available from the National Health Commission of China upon application.

\section{Compliance with ethical standards}

Conflicts of interest The authors have no conflicts of interest to declare that are relevant to the content of this article.

Ethical approval According to the Central University Research Ethics Committee at the University of Oxford, since this research use data collected before the project was formulated, where data are fully anonymous and not identifiable by researchers, an ethical approval process is waived.

Code availability Not applicable.

Open Access This article is licensed under a Creative Commons Attribution 4.0 International License, which permits use, sharing, adaptation, distribution and reproduction in any medium or format, as long as you give appropriate credit to the original author(s) and the source, provide a link to the Creative Commons licence, and indicate if changes were made. The images or other third party material in this article are included in the article's Creative Commons licence, unless indicated otherwise in a credit line to the material. If material is not included in the article's Creative Commons licence and your intended use is not permitted by statutory regulation or exceeds the permitted use, you will need to obtain permission directly from the copyright holder. To view a copy of this licence, visit http://creativecommons.org/licen ses/by/4.0/.

\section{References}

Alessandrini, M., Celotti, P., Gramillano, A., \& Lilla, M. (2017). The future of industry in Europe. Report for the European Committee of the Regions. Retrieved 27, June 2020, from https://espas.secur e.europarl.europa.eu/orbis/sites/default/files/generated/document/en/report_future_industry_form_ pdf.pdf.

Becker, G. (1962). Investment in human capital: A theoretical analysis. Journal of Political Economy, $70(5), 9-49$.

Becker, G. (1994). Human capital: A theoretical and empirical analysis with special reference to education (3rd ed.). Chicago, IL: The University of Chicago Press.

Berman, E., Lang, K., \& Siniver, E. (2003). Language-skill complementarity: Returns to immigrant language acquisition. Labour Economics, 10(3), 265-290.

Bin, E., \& Xu, G. (2017). Modern apprenticeship: The match between labor market supply and demand. Contemporary Vocational Education, 2, 4-8.

Cai, F., \& Du, Y. (2011). Wage increases, wage convergence, and the Lewis turning point in China. China Economic Review, 22(4), 601-610.

Chevalier, A. (2003). Measuring over-education. Economica, 70, 509-531.

Côté, J. (2014). Youth studies: Fundamental issues and debates. London: Palgrave Macmillan.

Démurger, S., Gurgand, M., Li, S., \& Yue, X. (2009). Migrants as second-class workers in urban China? A decomposition analysis. Journal of Comparative Economics, 37(4), 610-628.

Durazzi, N. (2018). The political economy of high skills: Higher education in knowledge societies. Ph.D. Thesis. The London School of Economics and Political Science, UK.

Dustmann, C., \& Fabbri, F. (2003). Language proficiency and labour market performance of immigrants in the UK. The Economic Journal, 113(489), 695-717. 
Fan, C. (2008). China on the move: Migration, the state, and the household. London: Routledge.

Feng, D. (2006). China's recent curriculum reform: Progress and problems. Planning and Changing, 37, 131-144.

Goodman, L. A. (1960). On the exact variance of products. Journal of The American Statistical Association, 55, 708-713.

Hall, P. A., \& Soskice, D. (2001). Varieties of capitalism: The institutional foundations of comparative advantage. Oxford: Oxford University Press.

Höpner, M. (2005). What connects industrial relations and corporate governance? Explaining Institutional Complementarity. Socio-Economic Review, 3(2), 331-358.

Huang, Z., Wang, T., \& Li, X. (2015). The political dynamics of educational changes in China. Policy Futures in Education, 14(1), 24-41.

Khor, N., Pang, L., Liu, C., Chang, F., Mo, D., Loyalka, P., et al. (2016). China's looming human capital crisis: Upper secondary educational attainment rates and the middle-income trap. The China Quarterly, 228, 905-926.

Klorer, E., \& Stepan, M. (2015). Off target: China's vocational education and training system threatens the country's rise to industrial superpower status. China Monitor, 24, 1-9.

Knight, J., Deng, Q., \& Li, S. (2011). The puzzle of migrant labour shortage and rural labour surplus in China. China Economic Review, 22(4), 585-600.

Kogan, I. (2004). Last hired, first fired? The unemployment dynamics of male immigrants in Germany. European Sociological Review, 20(5), 445-461.

Li, Q. (1999). The occupational mobility of migrant workers in mainland China cities. Sociological Studies, 3, 93-101.

Li, C. (2019). Regional variance in peasant workers' wage structures-case studies of peasant workers from the Yangtze River Delta and the Pearl River Delta firms. South China Journal of Economics, 33(11), 100-120.

Li, Q., \& Yuan, Z. (2016). Report on labour market skill gaps in China. Retrieved 29, November 2020, from https://www.tsinghua.edu.cn/_local/4/E6/DA/A12EB75B9D564353167D4F107C5_D711D 7DB_79EC7D.pdf?e=.pdf.

Liu, C., \& Chen, J. (2008). The urbanisation of the second-generation migrant workers: an analysis of the current status and the measurement of progress. Population Research, 32(5), 48-57.

Liu, Y., Xu, W., Shen, J., \& Wang, G. (2017). Market expansion, state intervention and wage differentials between economic sectors in urban China: A multilevel analysis. Urban Studies, 54(11), 2631-2651.

Lyu, L., \& Chen, Y. (2019). Parental migration and young migrants' wages in urban China: An exploratory analysis. Urban Studies, 56(10), 1968-1987.

Mincer, J. (1974). Schooling, experience and earnings. New York, NY: Columbia University Press.

Müller, W. (2005). Education and youth integration into European labour markets. International Journal of Comparative Sociology, 46, 461-485.

Ni, G. (2010). Children of migrant workers may be able to enter urban high schools. People's Daily, 24 March 2010. Retrieved 11, October 2020 from http://web.archive.org/web/20201011104717/http:// old.moe.gov.cn/publicfiles/business/htmlfiles/moe/s3607/201004/83284.html.

Saha, B., \& Sarkar, S. (1999). Schooling, informal experience, and formal sector earnings: A study of indian workers. Review of Development Economics, 3, 187-199.

Shavit, Y., \& Müller, W. (2000). Vocational secondary education. European Societies, 2(1), 29-50.

Sobel, M. E. (1986). Some new results on indirect effects and their standard errors in covariance structure models. Sociological Methodology, 16, 159-186.

Spence, A. M. (1974). Market signalling: Information transfer in hiring and related processes. Cambridge, MA: Harvard University Press.

Strayer, W. (2012). The returns to school quality: College choice and earnings. Journal of Labour Economics, 20(3), 475-503.

Tian, F. (2010). A study of the income gap between urban workers and migrant workers. Sociological Studies, 2, 87-105.

Tian, Y. (2013). The inter-generational difference in factors influencing the job choice of migrant workers. China Population Resource and Environment, 23, 81-88.

Wang, C. (2006). The employment status of out-flowing migrant workers and the protection of rights and interests in Jiangsu Province. Resource Document. National Bureau of Statistic Analysis Report Series. Retrieved 27, June 2020, from http://www.stats.gov.cn/ztjc/ztfx/fxbg/200601/t2006 0126_16006.html. 
Wang, W., \& Fan, C. (2012). Migrant workers' integration in urban China: Experiences in employment, social adaptation, and self-identity. Eurasian Geography and Economics, 53(6), 731-749.

Wang, H., Guo, F., \& Cheng, Z. (2015). A distributional analysis of wage discrimination against migrant workers in China's urban labour market. Urban Studies, 52(13), 2383-2403.

Wang, F., \& Mason, A. (2007). Population aging in China: Challenges, opportunities, and institutions. In Z. Zhao \& F. Guo (Eds.), Transition and change: China's population at the turn of the twenty-first century (pp. 177-196). Oxford: Oxford University Press.

Wang, Q., Ren, T., \& Liu, T. (2019). Training, skill-upgrading and settlement intention of migrants: evidence from China. Urban Studies, 56(13), 2779-2801.

Wen, L., \& Maani, S. (2017). A panel study of immigrants' overeducation and earnings in Australia. International Migration, 56(2), 177-200.

Wu, F., \& Zhang, J. (2007). Planning the competitive city-region: The emergence of strategic development plan in China. Urban Affairs Review, 42(5), 714-740.

Xiao, Y., \& Bian, Y. (2018). The influence of hukou and college education in China's labour market. Urban Studies, 55(7), 1504-1524.

Xie, G. (2012). Return to human capital and social integration of migrants in China. Social Sciences in China, 4, 103-124.

Zhang, Y. (2015). The matching between vocational education and labour demand in China. Education and Economy, 3, 9-14.

Zhang, S., Guo, F., \& Luo, Y. (2007). Wage differentials between rural migrants and urban residents in urban labor market. The Journal of Quantitative Economics, 3, 1-9.

Zhang, J., \& Peck, J. (2016). Variegated capitalism, Chinese style: Regional models, multi-scalar constructions. Regional Studies, 50(1), 52-78.

Nan Xiang is a doctoral candidate in Sociology at the Department of Sociology, The Chinese University of Hong Kong. Her research focuses on comparative education and educational inequality.

Yuxi Zhang is a postdoctoral research fellow at the Blavatnik School of Government, University of Oxford. 